\title{
Movement Influences Carambola Leaflet Chlorophyll Fluorescence and Temperature under Sunny Conditions
}

\author{
Thomas E. Marler and Patrick D. Lawton \\ College of Agriculture and Life Sciences, University of Guam, University of Guam Station, Mangilao, \\ Guam 96923
}

Additional index words. Averrhoa carambola, photochemical efficiency

\begin{abstract}
Leaflets of 'Arkin', 'B-10', 'Kary', and 'Sri Kembangan' carambola (Averrhoa carambola L.) trees were restrained in a horizontal position for $3.5 \mathrm{~h}$ during midday under full sun conditions to determine the influence of overriding natural leaflet movement on adaxial chlorophyll fluorescence and temperature. Induced chlorophyll fluorescence obtained after 30 minutes of dark adaptation following the period of full sun exposure was affected by leaflet movement. Restrained leaflets exhibited a variable fluorescence $\left(F_{v}\right) /$ peak fluorescence $\left(F_{m}\right)$ of 0.48 , while that of unrestrained leaflets was 0.65 . Adaxial leaflet temperature of restrained leaflets was $6 \mathrm{C}$ higher than that of leaflets that were allowed to move. The influence of leaflet movement on temperature or chlorophyll fluorescence was not different among the four cultivars. However, mean $\mathbf{F} / \mathbf{F}_{\mathrm{m}}$ of 'Kary' and 'Sri Kembangan' was lower than that of 'B- 10'. Our results indicate that the ability of carambola to change leaflet angle leads to lower temperature and higher photochemical efficiency than occurs when leaflets are not allowed to move naturally (vertically orient) under full sun conditions.
\end{abstract}

Carambola leaflet petiolules are equipped with a pulvinus that allows leaflet movement. Seismonastic movement (Ball, 1969) occurred with carambola leaflets in response to shaking the canopy (Marler and Zozor, 1992). A vertical leaflet orientation was rapidly achieved during shaking, followed by 1 to $2 \mathrm{~h}$ of petiolule movement to achieve the original nonstimulated position.

Satter (1979) reported that rapid mechanically stimulated leaf movements can occur in some species in response to other stimuli, such as high-intensity light. Indeed, Marler et al. (1994) reported that natural leaflet movement occurred during midday on sunny days for fully exposed carambola trees. This movement was not evident in fully exposed trees on cloudy days or in trees that were grown under neutral fabric shadecloth (50\% transmittance) regardless of the cloud cover.

Vertical leaf orientation reduces single-leaf radiation load under high light conditions (McMillen and McClendon, 1979), thus reducing the potential for damage by excessive light or heat. The objective of this study was to determine the influence of carambola leaflet movement during midday exposure to sunny conditions on leaflet temperature and chlorophyll fluorescence characteristics.

\section{Materials and Methods}

Seedlings of 'Golden Star' carambola were grafted with scions of 'Arkin', 'B-10', 'Kary', and 'Sri Kembangan' in August 1992. The plants were irrigated and fertilized as previously described (Marler et al., 1994). The containerized plants were maintained under 50\% shadecloth until 21 May 1993, when they were transferred to full sun and pruned to $45 \mathrm{~cm}$ in height.

Regrowth was $\approx 35 \mathrm{~cm}$ by 11 Sept., when four plants of each cultivar were randomly chosen and removed from the general population. One leaflet on each of these plants was restrained at $1000 \mathrm{HR}$ to orient the lamina perpendicular to the vertical. This was

Received for publication 20 Apr. 1994. Accepted for publication 22 Sept. 1994. The cost of publishing this paper was defrayed in part by the payment of page charges. Under postal regulations, this paper therefore must be hereby marked advertisement solely to indicate this fact. accomplished by sandwiching the petiolule and rachis within a spring-loaded clip. There was no direct influence of this method for restraining the leaflet on chlorophyll fluorescence, according to preliminary experiments. Leaflets that were restrained but shaded to provide a moderated light level exhibited chlorophyll fluorescence characteristics that did not differ from unrestrained leaflets. Moreover, leaflets that were restrained in this manner and given full sun exposure exhibited fluorescence characteristics that did not differ from leaflets restrained by stretching a thin-gauge wire underneath the lamina.

After $3.5 \mathrm{~h}$ of exposure to full sun, dark adaptation cuvettes were placed on the restrained laminae and an unrestrained leaflet that matched the restrained leaflet in orientation and exposure on each plant. Following 30 min of dark adaptation, induced chlorophyll fluorescence was determined with photosynthetic photon flux (PPF) of excitation light set at $950 \mu \mathrm{mol} \cdot \mathrm{m}^{-2} \cdot \mathrm{s}^{-1}(\mathrm{CF}-1000$ fluorometer; P.K. Morgan, Andover, Mass.). This PPF exceeds light saturation of net $\mathrm{CO}_{2}$ assimilation for carambola (Marler et al., 1994). The procedure was repeated on four more plants on 16 and 17 Sept., for a total of 12 replications. Days on which measurements were made were mostly sunny, with PPF ranging between 2200 and $2350 \mu \mathrm{mol} \cdot \mathrm{m}^{-2} \cdot \mathrm{s}^{-1}$ during the 3.5 -h period of exposure.

The influence of restraining leaflets on adaxial temperature and incident PPF was additional] y determined on 17 Sept. Temperature was measured by placing a thermistor (PP Systems, Stotfield, Hitchin, Herts, U. K.) on each restrained leaflet surface and a matched unrestrained leaflet surface at $1230 \mathrm{HR}$ and again at 1300 HR. Following surface temperature measurements, incident PPF was measured with a quantum sensor (PP Systems). The sensor was placed adjacent and parallel to restrained and matched unrestrained laminae for each plant, and PPF was recorded. This provided a total of eight temperature and PPF replications for each cultivar $\times$ leaflet treatment combination.

Chlorophyll fluorescence data were subjected to analysis of variance as a four cultivar $\times$ two leaflet treatment factorial in a randomized complete-block design. Each group of 16 trees (four per cultivar) for each measurement day was defined as a block. Temperature and PPF data were subjected to analysis of variance as a $4 \times 2$ factorial in a completely randomized design. 


\section{Results and Discussion}

The main sources of variation of cultivar and leaflet treatment were significant for fluorescence ratio [variable fluorescence $\left(\mathrm{F}_{\mathrm{v}}\right)$ / peak fluorescence $\left(\mathrm{F}_{\mathrm{m}}\right)$ ]. Blocks and the interaction of main effects were nonsignificant. Leaflets that received $3.5 \mathrm{~h}$ of sunlight while restrained to a horizontal position exhibited $>25 \%$ reduction in $\mathrm{F}_{v} /$ $\mathrm{F}_{\mathrm{m}}$ compared with leaflets that were allowed to change their angle to avoid the incident solar beam (Table 1). In addition, $F_{v}$ and $F_{m}$ were significantly reduced, and $t_{1 / 2}$ was significantly increased by restraining carambola leaflets, but these characteristics were not different among the other sources of variation. The $\mathrm{F}_{\mathrm{v}} / \mathrm{constant}$ fluorescence $\left(\mathrm{F}_{\mathrm{o}}\right)$ of carambola leaflets that were allowed to move was 1.88 , and this characteristic was significantly reduced by restraining leaflets to 0.96 . Forcing the leaflets to receive direct high light exposure for $3.5 \mathrm{~h}$ did not influence $\mathrm{F}$.

The calculated $\mathrm{F}_{\mathrm{v}} / \mathrm{F}_{\mathrm{m}}$ is proportional to the photochemical efficiency of a leaf (Demmig-Adams and Adams, 1992) and, thus, is highly useful in studying the integrity of the photosynthetic apparatus (Bolhar-Nordenkampf et al., 1989). A treatment that leads to reduced $F_{v} / F_{m}$ via reduction in $F_{v}$ (rather than an increase in $\mathrm{F}_{\mathrm{o}}$ ) may reduce photochemical efficiency through an increase in nonphotochemical quenching (Bolhar-Nordenkampf et al., 1989). Our data indicate that restraining carambola leaflets for several hours in sunlight leads to these results. The calculated $F_{v} / F_{o}$ is highly dependent on temperature and has been used to determine optimal growth temperatures for various plants (Burke, 1990; Ruter, 1993). The reduction in this characteristic by restraining carambola leaflets may indicate the presence of supraoptimal leaflet temperatures. The characteristic $t_{1 / 2}$ is the half rise time from $\mathrm{F}_{\mathrm{o}}$ to $\mathrm{F}_{\mathrm{m}}$ and is an indication of the rate of photochemical reaction (Bolhar-Nordenkampf et al., 1989).

Table 1. Chlorophyll fluorescence characteristics of carambola leaflets following $3.5 \mathrm{~h}$ of exposure to sunlight (PPF $=2200$ to 2350 $\left.\mu \mathrm{mol} \cdot \mathrm{m}^{-2} \cdot \mathrm{s}^{-1}\right)$. Restrained leaflets were not allowed to move in response to the solar beam. Unrestrained leaflets were allowed natural movement. Data were pooled over four cultivars; $n=48$.

\begin{tabular}{lccrr}
\hline \hline & \multicolumn{4}{c}{ Characteristic $^{\mathrm{z}}$} \\
Treatment & $\mathrm{F}_{\mathrm{o}}$ & $\mathrm{F}_{\mathrm{m}}$ & $\mathrm{F}_{\mathrm{v}} / \mathrm{F}_{\mathrm{m}}$ & $\mathrm{t}_{\mathrm{t} / 2}(\mathrm{~m} \mathrm{~s})$ \\
\hline Unrestrained & 455 & $1311 \mathrm{~A}^{\mathrm{y}}$ & $0.65 \mathrm{~A}$ & $74 \mathrm{~A}$ \\
Restrained & 382 & $747 \mathrm{~B}$ & $0.48 \mathrm{~B}$ & $108 \mathrm{~B}$
\end{tabular}

${ }^{\overline{ }} \mathrm{F}_{\mathrm{o}}=$ constant fluorescence, $\mathrm{F}_{\mathrm{m}}=$ peak fluorescence, $\mathrm{F}_{\mathrm{v}}=$ variable fluorescence, $t_{12}=$ half rise time from $F_{0}$ to $F_{m}$.

'Mean separation within columns by $\mathrm{F}$ test, $P \leq 0.01$.

Table 2. Chlorophyll fluorescence characteristics of carambola leaflets following $3.5 \mathrm{~h}$ of exposure to sunlight (PPF $=2200$ to 2350 $\left.\mu \mathrm{mol} \cdot \mathrm{m}^{-2} \cdot \mathrm{s}^{-1}\right)$. Data were pooled over restrained and unrestrained treatments; $\mathrm{n}=24$.

\begin{tabular}{lccl}
\hline & \multicolumn{3}{c}{ Characteristic $^{z}$} \\
\cline { 2 - 4 } Cultivar & $\mathrm{F}_{\mathrm{o}}$ & $\mathrm{F}_{\mathrm{m}}$ & $\mathrm{F}_{\mathrm{v}} / \mathrm{F}_{\mathrm{m}}$ \\
\hline B-10 & 382 & 1077 & $0.62 \mathrm{a}$ \\
Arkin & 380 & 1009 & $0.58 \mathrm{ab}$ \\
Sri Kembangan & 404 & 987 & $0.56 \mathrm{~b}$ \\
Kary & 513 & 1170 & $0.54 \mathrm{~b}$
\end{tabular}

${ }^{\bar{z}} \mathrm{~F}_{\mathrm{o}}=$ constant fluorescence, $\mathrm{F}_{\mathrm{m}}=$ peak fluorescence, $\mathrm{F}_{v}=$ variable fluorescence.

'Mean separation within columns by Duncan's multiple range test, $P \leq 0.05$.
'B- 10' leaflets had a higher mean $\mathrm{F}_{\mathrm{v}} / \mathrm{F}_{\mathrm{m}}$ than those of 'Sri Kembangan' and 'Kary' (Table 2). No other differences occurred among the cultivars.

No differences in adaxial leaflet temperature or incident PPF occurred among the cultivars; however, the leaflet treatments differed in temperature and incident PPF $(P \leq 0.01)$. Restrained leaflets were $40 \pm 1 \mathrm{C}$, whereas leaflets that were allowed to naturally change leaflet angle were $34 \pm 1 \mathrm{C}(\mathrm{n}=32)$. Air temperature was $33 \mathrm{C}$, leaflet movement thus maintained adaxial temperature to within $1 \mathrm{C}$ of ambient. However, restrained leaflets were $7 \mathrm{C}$ above ambient on average. Incident PPF parallel to restrained leaflets was $2285 \pm 16 \mu \mathrm{mol} \cdot \mathrm{m}^{-2} \cdot \mathrm{s}^{-1}$, but was only $1181 \pm 123$ $\mu \mathrm{mol} \cdot \mathrm{m}^{-2} \cdot \mathrm{s}^{-1}$, parallel to unrestrained leaflets $(\mathrm{n}=32)$.

Ludlow and Bjorkman (1984) also reported little or no change in $\mathrm{F}$. but a large decline in $\mathrm{F}_{\mathrm{m}}$, (at $77 \mathrm{~K}$ ) of water-stressed Macroptilium atropurpureum DC. 'Siratro' leaves that were restrained compared with leaves that were allowed to change their angle to avoid the incident light. Changing leaf angle also reduced or prevented direct heat injury that was measured on leaves that were restrained in sunlight for several hours.

Active leaf movement to orient the lamina parallel to the incident radiation is an important morphological adaptation for protecting from leaf damage caused by excessive light (Begg, 1980; Demmig-Adams and Adams, 1992). Our results indicate that the presence of pulvini in carambola petiolules protects against substantial increase in leaflet temperature and loss of photochemical efficiency during sunny conditions. Furthermore, based on the small range of genotypic variability in this study, there may be differences among carambola cultivars with respect to maintenance of photochemical efficiency under high solar input during midday in tropical geographic regions.

\section{Literature Cited}

Ball, N.G. 1969. Nastic responses, p. 287. In: M.B. Wilkins (ed.). The physiology of plant growth and development. McGraw-Hill, New York.

Begg, J.E. 1980. Morphological adaptations of leaves to water stress, p. 33342. In: N.C. Turner and P.J. Kramer (eds.). Adaptation of plants to water and high temperature stress. Wiley and Sons, New York.

Bolhar-Nordenkampf, H. F., S.P. Long, N.R. Baker, G. Oquist, U. Schreiber, and E.G. Lechner. 1989. Chlorophyll fluorescence as a probe of the photosynthetic competence of leaves in the field: A review of current instrumentation. Functional Ecol. 3:497-514.

Burke, J.J. 1990. Variation among species in the temperature dependence of the reappearance of variable fluorescence following illumination. Plant Physiol. 93:652-656.

Demmig-Adams, B. and W. W. Adams HI. 1992. Photoprotection and other responses of plants to high light stress. Annu. Rev. Plant Physiol. Plant Mol. Biol. 43:599-626.

Ludlow, M.M. and O. Bjorkman. 1984. Paraheliotropic leaf movement as a protective mechanism against drought-induced damage to primary photosynthetic reactions: damage by excessive light and heat. Planta 161:505-518.

Marler, T. E., B. Schaffer, and J.H. Crane. 1994. Developmental light level affects growth, morphology, and leaf physiology of young carambola trees. J. Amer. Soc. Hort. Sci. 119:711-718.

Marler, T.E. and Y. Zozor. 1992. Carambola growth and leaf gasexchange responses to seismic or wind stress. HortScience 27:913-915. McMillen, G.G. and J.H. McClendon. 1979. Leaf angle: An adaptive feature of sun and shadeleaves. Bet. Gaz. 14:437-442.

Ruter, J.M. 1993. Foliar heat tolerance of two hybrid hollies. HortScience 28:650-652.

Satter, R.L. 1979. Leaf movements and tendril curling, p. 442484. In: W. Haupt and M.E. Feinleib (eds.). Physiology of movements. SpringerVerlag, Berlin. 